\title{
Hormonal evaluation and mutation screening for steroid 21-hydroxylase deficiency in patients with unilateral and bilateral adrenal incidentalomas
}

\author{
Attila Patócs, Miklós Tóth, Csaba Barta ${ }^{1}$, Mária Sasvári-Székely ${ }^{1}$, Ibolya Varga, Nikolette Szücs, Csilla Jakab, \\ Edit Gláz and Károly Rácz \\ 2nd Department of Medicine and ${ }^{1}$ Department of Medical Chemistry, Molecular Biology and Pathobiochemistry, Faculty of Medicine, \\ Semmelweis University, H-1088 Budapest, Szentkirályi u. 46, Hungary \\ (Correspondence should be addressed to K Rácz; Email: racz@bel2.sote.hu)
}

\begin{abstract}
Objective: The aims of the present study were (a) to examine the occurrence of 21-hydroxylase gene (CYP21) mutations in patients with unilateral and bilateral adrenal incidentalomas and (b) to correlate the results of mutation screening with hormonal parameters of 21-hydroxylase deficiency.

Design: The frequency of the eight commonly occurring CYP21 mutations in blood DNA samples of 19 patients with bilateral, as well as in blood and tumoral tissue DNA samples of 31 patients with unilateral adrenal incidentalomas, was determined. In all patients, hormonal evaluation for 21-hydroxylase deficiency was performed using measurements of basal and ACTH-stimulated plasma 17-hydroxyprogesterone (17-OHP) concentrations.

Methods: Blood and tumoral DNA samples were analyzed by allele-specific PCR for the detection of the eight commonly occurring CYP21 mutations (deletion/large gene conversion, intron 2 splicing, Ile172Asn, exon 6 cluster, Val281Leu, Leu307insT, Gln318Stop and Arg356Trp mutations). Plasma 17-OHP concentrations were measured by radioimmunoassay.

Results: Of the 19 patients with bilateral adrenal incidentalomas, one patient had homozygous (Val281Leu) and three patients had heterozygous germline CYP21 mutations (Val281Leu in two cases and Arg356Trp in one case). Heterozygous germline CYP21 mutations were also detected in five of the 31 patients with unilateral adrenal incidentalomas (Ile172Asn in three cases and Val281Leu in two cases). Mutation screening of tumoral DNA in unilateral incidentalomas showed the presence of corresponding germline mutations but no additional somatic mutations were found. ACTH-stimulated plasma 17-OHP concentrations were above $1500 \mathrm{ng} / \mathrm{dl}$ in all patients with bilateral incidentalomas who had homozygous and heterozygous CYP21 mutations, but heterozygous carriers with unilateral incidentalomas had highly variable ACTH-stimulated plasma 17-OHP levels (between 111 and $1705 \mathrm{ng} / \mathrm{dl}$ ).

Conclusions: These results suggest a similar frequency of germline CYP21 mutations in patients with bilateral and unilateral adrenal incidentalomas $(21.1 \%$ and $16.1 \%$ respectively). Therefore, it cannot be ruled out that, in at least some patients, CYP21 mutations may play a role in the pathomechanism of bilateral and unilateral adrenal incidentalomas. However, the lack of clear association of CYP21 mutations with increased ACTH-stimulated plasma 17-OHP response, especially in patients with unilateral incidentalomas, suggests that the effect of CYP21 mutations on adrenocortical tumor formation may also involve mechanism(s) independent of ACTH-induced changes in 17-OHP secretion.
\end{abstract}

European Journal of Endocrinology 147 349-355

\section{Introduction}

Adrenal incidentalomas constitute a rather common finding in clinical practice $(1,2)$. The current prevalence of unsuspected adrenal tumors is approximately $2-4 \%$ in abdominal computed tomography (CT) scan series (3-5), but autopsy studies indicate a higher frequency (6-8). In most cases, these tumors are unilateral, but in $10-18 \%$ of all cases the tumors involve both adrenals $(9,10)$.

The majority of surgically removed adrenal incidentalomas have been described histologically as benign adrenocortical adenomas $(1,3,7,8,11)$. Except for a small number of patients presenting with subclinical Cushing's syndrome or primary aldosteronism (12, 13), these benign adrenocortical adenomas have been 
considered as being clinically non-functioning, although slight abnormalities in the function of the hypothalamic-pituitary-adrenal axis, perhaps suggesting an occult secretion of corticosteroids, have also been documented (14-16). Perhaps more interestingly, an exaggerated plasma 17-hydroxyprogesterone (17-OHP) response after adrenocorticotropin (ACTH) administration present in $25-71 \%$ of the patients has been documented in several series of studies, including a large number of patients with incidental adrenal tumors $(10,16-22)$. The latter observations led to the proposal that undiagnosed mild forms of congenital 21-hydroxylase deficiency or a heterozygous state for this disorder, which results in decreased cortisol secretion and consequently increased ACTH secretion, may be a predisposing factor for the development of incidental adrenocortical tumors. Consistent with this concept, one study showed that adrenocortical adenomas may be present in $82 \%$ of homozygous patients as well as in $45 \%$ of heterozygous carriers for congenital 21-hydroxylase deficiency (23).

The occurrence of disease-causing 21-hydroxylase gene (CYP21) mutations in peripheral blood and/or tumoral tissue samples of patients with different types of adrenal tumors has been examined in two recent studies $(24,25)$. Beuschlein et al. (24) investigated the mutational spectrum and mRNA expression of the CYP21 gene in six aldosterone-producing adenomas, seven cortisol-producing adenomas, four adrenal carcinomas and two adrenocortical incidentalomas. They found that neither of the two adrenocortical incidentalomas had homozygous or heterozygous CYP21 mutations, although the mRNA contents of the two tumors were markedly lower than those measured in aldosterone-producing adenomas. In the study of Kjellman et al. (25), 27 patients with sporadic adrenocortical tumors including six patients with hormonally silent benign tumors were screened and the results showed the absence of the commonly occurring CYP21 mutations in these patients. However, the results of the two studies do not entirely contradict the previously proposed role of CYP21 mutations in the development of hormonally inactive adrenal tumors, because an ACTH-stimulation test had not been performed and, therefore, it is not known whether or not the few patients studied could have an exaggerated 17-OHP response. In addition, the occurrence of CYP21 mutations has not been previously examined in patients with bilateral adrenal incidentalomas. We therefore performed the present studies with two principal aims: (a) to examine the occurrence of CYP21 mutations in patients with unilateral and bilateral adrenal incidentalomas and (b) to correlate the results of mutation screening with hormonal evidence of 21-hydroxylase deficiency using measurements of basal and ACTH-stimulated plasma 17-OHP concentrations in the same patients with unilateral and bilateral adrenal tumors.

\section{Patients and methods}

\section{Patients}

The patients were evaluated for adrenal incidentalomas at the 2nd Department of Medicine, Faculty of Medicine, Semmelweis University between 1995 and 2000. Nineteen patients (14 females and five males, mean age 54 years) had bilateral adrenal tumors which were discovered during abdominal ultrasound or CT performed for unrelated reasons. None of the patients had clinical evidence of hormonal overproduction. In all patients, a detailed endocrine evaluation was performed, which excluded primary aldosteronism, Cushing's syndrome, hyperandrogenism and pheochromocytoma. In all these patients, CT scans showed homogenous adrenal lesions whose size remained unchanged during follow-up lasting 12-60 months. None of the patients underwent adrenal surgery.

The study also included 31 patients (27 females and four males, mean age 51 years) who were operated on for unilateral adrenal incidentalomas between 1995 and 2000. In these patients, hormonal evaluation performed before unilateral adrenalectomy failed to prove hormonal overproduction disorders. Although surgery was performed in all cases because of some suspicion of malignancy because of a tumor diameter larger than $4 \mathrm{~cm}$ or an increase in tumor size during patient follow-up, none of the tumors proved to be malignant and in all cases histological examination showed benign adrenocortical adenomas.

\section{Endocrine evaluation}

In all patients, hormonal evaluation included measurements of plasma cortisol, 17-OHP, androstendione, dehydroepiandrosterone and testosterone at $0800 \mathrm{~h}$ under resting conditions, as well as plasma cortisol measurements after overnight low-dose dexamethasone administration. Plasma renin activity and aldosterone were also determined under resting conditions and in an upright posture after furosemide administration.

All patients underwent an ACTH stimulation test using $2 \mathrm{mg}$ synthetic $\mathrm{ACTH}_{1-24}$ (Cortrosyn Depot; Organon, Oss, The Netherlands). An i.m. injection was given at $1400 \mathrm{~h}$, and blood was drawn the next morning between 0800 and $0900 \mathrm{~h}$ for measurements of plasma cortisol and 17-OHP. In patients with unilateral adrenal incidentalomas, the test was performed both before and after adrenal surgery. In a previous study, the plasma 17-OHP concentrations (means \pm S.D.) after this ACTH stimulation test in 78 patients with unilateral adrenal incidentalomas and in 60 normal subjects were $1926.6 \pm 1801.1 \mathrm{ng} / \mathrm{dl} \quad(58.3 \pm 54.5$ $\mathrm{nmol} / \mathrm{l})$ and $601.5 \pm 274.3 \mathrm{ng} / \mathrm{dl}(18.2 \pm 8.3 \mathrm{nmol} / \mathrm{l})$ respectively (16). None of the patients from this previous study was included in the present study. 
Plasma cortisol, 17-OHP, androstenedione, dehydroepiandrosterone, aldosterone and testosterone concentrations were measured with previously published radioimmunoassay methods, using highly specific antisera $(26,27)$. The intra-assay coefficient of variation for these assays was between $6 \%$ and $10 \%$, and the interassay coefficient of variation was between $5 \%$ and $9 \%$. Plasma renin activity was determined using a commercially available kit (Rianen; DuPont, Boston, MA, USA).

\section{Mutation analysis of the CYP21 gene}

Written informed consent for mutation analysis was obtained from all patients. The use of adrenal tumor samples for molecular biological studies was approved by the local Ethical Committee of Semmelweis University.

Genomic DNA was extracted from peripheral blood leukocytes. Samples of adrenal tumoral tissues were collected at adrenalectomy, frozen in liquid nitrogen, and stored at $-80^{\circ} \mathrm{C}$ until analyzed. The tissues were homogenized and used for DNA extraction. DNA was extracted from peripheral blood leukocytes and from adrenal tumor homogenates using the DNA Isolation Kit for Mammalian Blood (Boehringer Mannheim Corp., Indianapolis, IN, USA).

DNA samples obtained from peripheral blood and tumoral tissues were analyzed for deletion/large gene conversion of the CYP21 gene locus, as described (28). Mutation analysis of the CYP21 gene by allele-specific PCR, after selection against the CYP21 pseudogene was performed using the method of Wedell \& Luthman (29). CYP21 was first selectively amplified by PCR using oligonucleotides CYP55, 5'-CCTGTCCTTGGGAGACTACT and CYP12, 5'-ACTGTGTTTACAGGGGGGAG for a $2080 \mathrm{bp}$ fragment and CYP1, 5'-TTCAGGCGATTCAGGAAGGC and CYP48, 5'-CAGAGCAGGGAGTAGTCTC for a $1129 \mathrm{bp}$ fragment of the CYP21 gene. The PCR products containing the selectively amplified CYP21 fragments were further analyzed by allelespecific PCR using oligonucleotide sequences for the detection of intron 2 splicing, Ile172Asn, exon 6 cluster, Val281Leu, Leu307insT, Gln318Stop and Arg356Trp mutations. After an initial denaturation at $96^{\circ} \mathrm{C}$ for $3 \mathrm{~min}, 30$ cycles at $96^{\circ} \mathrm{C}$ for $1 \mathrm{~min}, 56^{\circ} \mathrm{C}$ for $30 \mathrm{~s}$ and $72^{\circ} \mathrm{C}$ for 3 min were performed in a buffer containing $1.5 \mathrm{mM} \mathrm{MgCl} 2,50 \mathrm{mM} \mathrm{KCl}, 10 \mathrm{mM}$ Tris- $\mathrm{HCl}, 0.2 \mathrm{mM}$ deoxynucleotide triphosphate, $1 \mathrm{U}$ Taq polymerase
(Pharmacia Biotech, Uppsala, Sweden), 0.15 or $0.5 \mu \mathrm{M}$ oligonucleotide primers (Invitrogene Life Technologies, Glasgow, UK) and 5\% glycerol. The final extension was accomplished at $72{ }^{\circ} \mathrm{C}$ for $10 \mathrm{~min}$. The PCR products were separated by agarose gel electrophoresis and visualized by ethidium bromide staining.

\section{Statistical analysis}

The results are expressed as means \pm S.D. Statistical analysis included non-parametric tests (MannWhitney-Wilcoxon test, Spearman rank correlation). $P<0.05$ was considered to be statistically significant.

\section{Results}

The clinical data of patients with bilateral and unilateral adrenal incidentalomas are shown in Table 1. The mean age was similar in the two groups of patients. There was a high female/male ratio in both groups of patients. The size of unilateral incidentalomas (31 \pm $50 \mathrm{~mm}$ ) was larger as compared with the size of bilateral adrenal tumors $(24 \pm 22$ and $23 \pm 28 \mathrm{~mm}$ in the left and right incidentalomas respectively).

Basal plasma 17-OHP concentrations were similar in the two groups of patients with adrenal tumors $(59 \pm 58$ and $67 \pm 65 \mathrm{ng} / \mathrm{dl}$ in patients with unilateral and bilateral adrenal tumors respectively). After ACTH administration, plasma 17-OHP was substantially increased in both groups with higher levels attained in patients with bilateral $(1770 \pm 1459 \mathrm{ng} / \mathrm{dl})$ compared with those

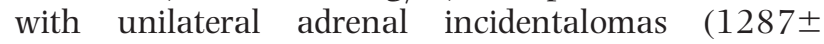
$731 \mathrm{ng} / \mathrm{dl})$. However, this difference between the two groups was not statistically significant. The ACTHstimulated plasma 17-OHP concentrations of individual patients indicated that 14 of the 19 patients with bilateral tumors and 19 of the 31 patients with unilateral adrenal tumors showed an exaggerated response to ACTH stimulation $(>1000 \mathrm{ng} / \mathrm{dl})$, which is usually considered as hormonal evidence for a decreased activity of the 21-hydroxylase enzyme. In contrast, after adrenal surgery none of the 31 patients with unilateral adrenal incidentalomas had an ACTH-stimulated plasma 17-OHP concentration above $1000 \mathrm{ng} / \mathrm{dl}$. The difference in ACTH-stimulated plasma 17-OHP levels before $(1287 \pm 731 \mathrm{ng} / \mathrm{dl})$ and after $(349 \pm 217 \mathrm{ng} / \mathrm{dl})$ adrenal surgery was statistically significant $(P<0.05)$.

Table 1 Clinical data of patients with bilateral and unilateral adrenal incidentalomas.

\begin{tabular}{lccccc}
\hline & & & \multicolumn{2}{c}{ Age (years) } & \\
\cline { 4 - 5 } Incidentaloma & No. of patients & Female/male & Mean & Range & $\begin{array}{c}\text { Tumor size (mm) } \\
(\text { mean } \pm \text { S.D.) }\end{array}$ \\
\hline Bilateral & 19 & $14 / 5$ & 54 & $42-67$ & $24 \pm 22$ (left) \\
Unilateral & 31 & $27 / 4$ & 51 & $28-76$ & $31 \pm 50$ \\
\hline
\end{tabular}


Mutation screening performed in peripheral blood DNA samples of 19 patients with bilateral adrenal incidentalomas revealed a Val281Leu mutation in a homozygous form in one patient. In addition, three patients had CYP21 mutations in heterozygous forms (Val281Leu in two cases and Arg356Trp in one case). Thus, homozygous or heterozygous mutations were detected in $21.1 \%$ of patients with bilateral adrenal tumors. In all these patients, ACTH-stimulated plasma 17-OHP levels were above $1500 \mathrm{ng} / \mathrm{dl}$ (Table 2).

Genetic screening in both peripheral blood and tumoral tissue DNA samples of 31 patients with unilateral adrenal incidentalomas failed to show CYP21 mutations in homozygous forms. However, five patients with heterozygous mutations were identified $(16.1 \%$ of patients with unilateral tumors) which showed the presence of the same mutations in both peripheral blood and tumoral tissue DNA (Ile172Asn in three cases and Val281Leu in two cases). Interestingly, only two of the five patients had increased ACTH-stimulated plasma 17-OHP levels suggestive of a decreased activity of the 21-hydroxylase enzyme (Table 2).

Comparison of the results of genetic screening and hormonal data indicated a considerable degree of divergence between the mutational spectrum of the CYP21 gene and ACTH-stimulated plasma 17-OHP concentrations. As shown in Fig. 1, homozygous or heterozygous CYP21 gene mutations were frequently present in patients with bilateral adrenal incidentalomas who had ACTH-stimulated plasma 17-OHP levels above $1500 \mathrm{ng} / \mathrm{dl}$, although these mutations were absent in a patient showing the highest plasma 17-OHP level after ACTH stimulation. The discrepancy between genetic and hormonal studies was even more apparent in patients with unilateral incidentalomas, as ACTHstimulated plasma 17-OHP concentrations remained in the normal or low range in three of the five heterozygous carriers.

\section{Discussion}

In the present study, we performed hormonal evaluation and mutation screening for 21-hydroxylase deficiency in a large number of patients with unilateral and bilateral adrenal incidentalomas. A homozygous germline Val281Leu mutation was found in one of the 19 patients with bilateral adrenal tumors, this patient had a markedly increased plasma 17-OHP response to ACTH stimulation. Since normal basal 17-OHP together with a markedly increased ACTHstimulated 17-OHP concentration predict a partial decrease of 21-hydroxylase enzyme activity, and homozygous Val281Leu mutation results in a partial inactivation of the enzyme (30), this patient appears to represent a clinically unrecognized case of the nonclassical form of congenital 21-hydroxylase deficiency. In agreement with this finding, a few cases of congenital 21-hydroxylase deficiency presenting as bilateral adrenal masses in middle-aged or older subjects have already been reported (31-33).

In patients with bilateral adrenal incidentalomas, germline CYP21 mutations were also present in a heterozygous form. Of the 19 patients, two patients were identified as heterozygous carriers for a Val281Leu mutation and one patient was a heterozygous carrier for a Arg356Trp mutation. In all these three patients ACTH-stimulated plasma 17-OHP

Table 2 Basal and ACTH-stimulated plasma 17-OHP concentrations in patients with homozygous and heterozygous CYP21 mutations.

\begin{tabular}{|c|c|c|c|c|c|}
\hline \multirow{2}{*}{$\begin{array}{l}\text { Adrenal } \\
\text { incidentaloma }\end{array}$} & \multirow[b]{2}{*}{ Patient no. } & \multirow[b]{2}{*}{ Mutation } & \multirow{2}{*}{$\begin{array}{l}\text { Adrenal tumor } \\
\qquad(\mathrm{mm})\end{array}$} & \multicolumn{2}{|c|}{ Plasma 17-OHP (ng/dl) } \\
\hline & & & & Basal & ACTH-stimulated \\
\hline \multicolumn{6}{|l|}{ Bilateral } \\
\hline & 1 & $\begin{array}{l}\text { Val281Leu } \\
\text { homozygous }\end{array}$ & $\begin{array}{l}43 \text { (left) } \\
34 \text { (right) }\end{array}$ & 237 & 5012 \\
\hline & 2 & $\begin{array}{l}\text { Val281Leu } \\
\text { heterozygous }\end{array}$ & $\begin{array}{l}20 \text { (left) } \\
30 \text { (right) }\end{array}$ & 125 & 2570 \\
\hline & 3 & $\begin{array}{l}\text { Val281Leu } \\
\text { heterozygous }\end{array}$ & $\begin{array}{l}25 \text { (left) } \\
10 \text { (right) }\end{array}$ & 39 & 2118 \\
\hline & 4 & $\begin{array}{l}\text { Arg356Trp } \\
\text { heterozygous }\end{array}$ & $\begin{array}{l}20 \text { (left) } \\
45 \text { (right) }\end{array}$ & 19 & 1505 \\
\hline Unilateral & 1 & $\begin{array}{l}\text { lle172Asn } \\
\text { heterozygous }\end{array}$ & 20 (left) & 197 & 1142 \\
\hline & 2 & $\begin{array}{l}\text { lle172Asn } \\
\text { heterozygous }\end{array}$ & 40 (right) & 31 & 111 \\
\hline & 3 & $\begin{array}{l}\text { lle172Asn } \\
\text { heterozygous }\end{array}$ & 20 (left) & 106 & 717 \\
\hline & 4 & $\begin{array}{l}\text { Val281Leu } \\
\text { heterozygous }\end{array}$ & 35 (right) & 36 & 247 \\
\hline & 5 & $\begin{array}{l}\text { Val281Leu } \\
\text { heterozygous }\end{array}$ & 32 (right) & 49 & 1705 \\
\hline
\end{tabular}




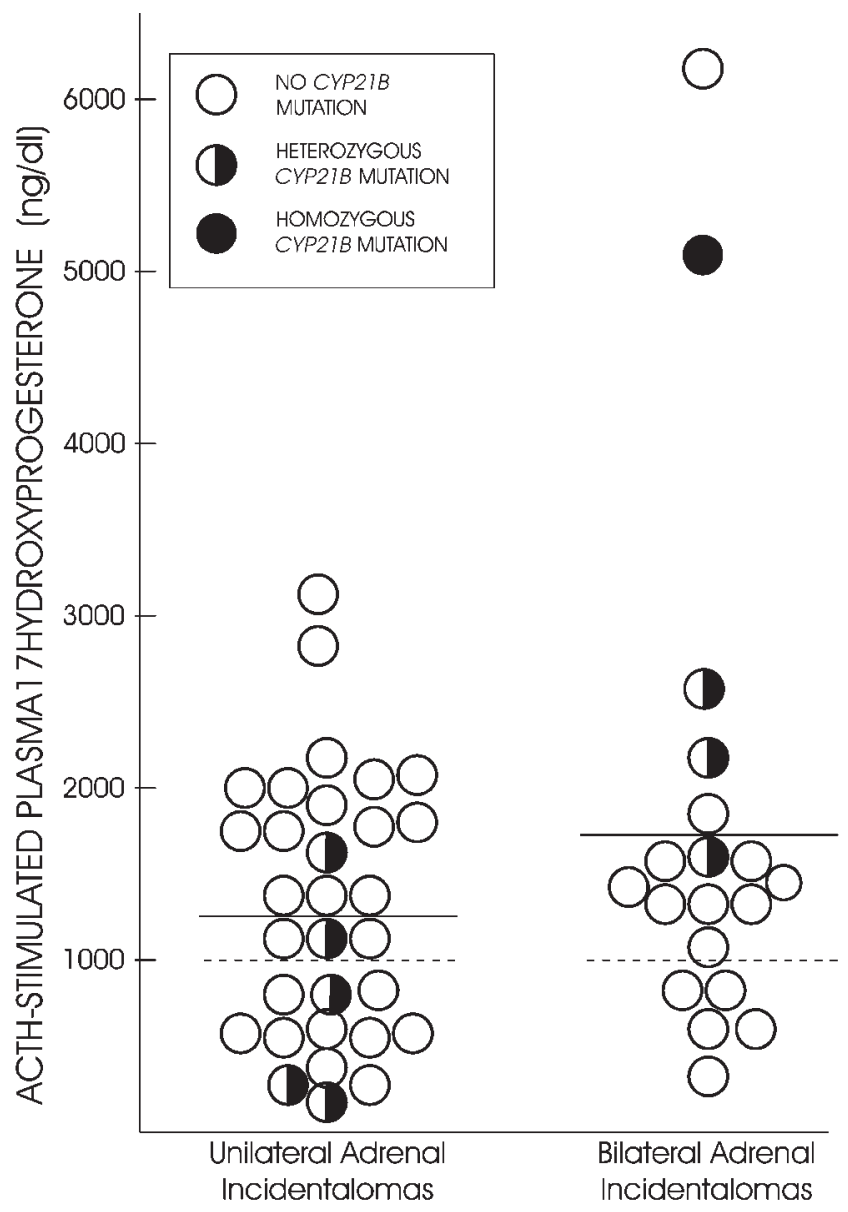

Figure $1 \mathrm{ACTH}$-stimulated plasma 17-OHP concentrations in patients with unilateral and bilateral adrenal incidentalomas. Each symbol represents one patient studied. Solid horizontal lines are means. Symbols above the broken lines correspond to patients in whom impairment of the 21-hydroxylase enzyme was considered.

concentrations were also well above the normal range $(>1500 \mathrm{ng} / \mathrm{dl})$, but these hormone levels were lower than that found in a patient with a homozygous Val281Leu mutation. An exaggerated 17-OHP response to ACTH stimulation has been reported in several earlier studies in heterozygous carriers of congenital 21-hydroxylase deficiency (34-36). However, it is difficult to explain why a heterozygous state results in a mild decrease of enzyme activity in the presence of a non-mutated allelele.

It has been shown that patients with bilateral adrenal incidentalomas have a significantly higher ACTHstimulated plasma 17-OHP response compared with those with unilateral tumors, and that increased plasma 17-OHP levels suggestive of 21-hydroxylase deficiency are more frequent in patients with bilateral than in unilateral tumors (17). Our study also showed higher ACTH-stimulated plasma 17-OHP concentrations in patients with bilateral adrenal incidentalomas, although the difference between patients with bilateral and unilateral tumors was not statistically significant.

In our study, heterozygous germline CYP21 mutations were also detected in five of the 31 patients with unilateral adrenal incidentalomas (Ile172Asn in three cases and Val281Leu in two cases). However, the ACTH-stimulated plasma 17-OHP concentrations in three of the five patients failed to reflect the heterozygous carrier state $(<1000 \mathrm{ng} / \mathrm{dl})$. The discordance between the results of mutation screening and ACTHstimulated plasma 17-OHP levels in these three patients with unilateral adrenal incidentalomas is not fully understood. It has been shown that not all heterozygous carriers show an exaggerated plasma 17-OHP response to ACTH stimulation (37), which indicates that the stimulation test commonly used to document a partial deficiency of 21-hydroxylase enzyme is not always a reliable tool to detect heterozygous carriers. Other studies also showed a remarkable clinical and hormonal heterogeneity of homozygous patients or heterozygous carriers $(38,39)$, suggesting that other genes or other effects involved in the metabolism of adrenal steroids may influence the clinical and/or hormonal abnormalities present in these patients. Alternatively, it cannot be ruled out that the effect of CYP21 mutations on adrenocortical tumor formation (23) may involve mechanism(s) independent of the ACTHinduced changes in 17-OHP secretion.

The CYP21 gene is a frequent target of mutations, and congenital 21-hydroxylase deficiency is the most frequent autosomal recessive disorder in the human. The prevalence of 21-hydroxylase deficiency in the Caucasian population has been estimated as one in 1000 , but selective groups may have a higher prevalence (39-42). Based on plasma 17-OHP responses to ACTH stimulation, heterozygous carrier frequencies have been estimated as one in 16 for Caucasians (42). Molecular genetic screening of normal newborn infants in New Zealand showed that one in 20 were heterozygous for CYP21B mutations, which implies a disease frequency similar to that estimated in the Caucasian population (43). In our study, the detection of one homozygous and three heterozygous germline mutations in 19 patients with bilateral $(21.1 \%)$, and five heterozygous germline mutations in 31 patients with unilateral incidentalomas $(16.1 \%)$ suggests a higher frequency of mutations in both groups of adrenal tumors compared with that found in the general European population.

Finally, the results of the present study also indicate that increased ACTH-stimulated plasma 17-OHP levels can be detected in a considerable proportion of patients with unilateral and bilateral adrenal incidentalomas who do not have homozygous and heterozygous mutations of the CYP21 gene. The reason for increased 17-OHP levels in these patients remains unknown, but several possibilities can be considered. The mutation screening method used in our study 
has been proved to detect homozygous normal, homozygous mutant or heterozygous genotypes for the eight commonly occurring mutations with the exception of heterozygous deletion $(28,29,44)$, which could result in some underestimation of the occurrence of heterozygous carriers. However, it is unlikely that heterozygous deletions not revealed by our method significantly influenced the mutational spectrum detected in our patients. In our study, we also excluded the possibility that the exaggerated plasma 17-OHP response to ACTH in patients with no detectable germline CYP21 mutations was due to somatic mutations, since mutation screening in patients with unilateral adrenal incidentalomas revealed the same results in peripheral blood and tumoral DNA samples with no additional mutations in tumoral DNA. It may be relevant, however, that earlier studies showed down-regulation of 21-hydroxylase mRNA in incidental adrenal tumors $(24,45)$. Obviously, low expression of 21-hydroxylase mRNA, if it occurs in the absence of CYP21 mutations, could result in a decreased amount of the enzyme, although the mechanism responsible for low 21-hydroxylase mRNA expression in these tumors remains to be elucidated. Alternatively, it is also possible that mechanisms other than impairment of 21hydroxylase activity should be considered, since decreased activity of the $11 \beta$-hydroxylase enzyme resulting in increased ACTH-stimulated plasma 17-OHP levels in patients with adrenal incidentalomas has already been documented (19).

\section{Acknowledgements}

This work was supported by grants from the Ministry of Health (ETT 178/2000) and from the Ministry of Education of Hungary (FKFP 0611/2000).

\section{References}

1 Kloos RT, Gross MD, Francis IR, Korobkin M \& Shapiro B. Incidentally dicovered adrenal masses. Endocrine Reviews 199516 460-483.

2 Ross NS \& Aron DC. Hormonal evaluation of the patient with an incidentally discovered adrenal mass. New England Journal of Medicine $19903231401-1405$.

3 Copeland PM. The incidentally discovered adrenal mass. Annals of Internal Medicine 199398 940-945.

4 Glazer HS, Weyman PJ, Sagel SS, Levitt RG \& McClennan BL. Nonfunctioning adrenal masses: incidental discovery on computed tomography. American Journal of Roentgenology 1982139 81-85.

5 Peppercorn PD, Grossman AB \& Rezneck RH. Imaging of incidentally discovered adrenal masses. Clinical Endocrinology $1966 \mathbf{4 8}$ 379-388.

6 Griffing G. Editorial: A-I-D-S: The new endocrine epidemic. Journal of Clinical Endocrinology and Metabolism 199479 1530-1531.

7 Hedeland H, Östberg G \& Hökfelt B. On the prevalence of adrenocortical adenomas in an autopsy material in relation to hypertension and diabetes. Acta Medica Scandinavica $1968 \mathbf{1 8 4}$ $211-214$.
8 Russel R, Masi A \& Richter E. Adrenal cortical adenomas and hypertension. A clinical pathologic analysis of 690 cases with matched controls and a review of the literature. Medicine 1972 $51211-215$.

9 Kasperlik-Zaluska AA, Roslonowska E, Slowinska-Srzednicka J, Migdalska B, Jeske W, Makowska A et al. Incidentally discovered adrenal mass (incidentaloma): investigation and management of 208 patients. Clinical Endocrinology 199746 29-37.

10 Mantero F, Terzolo M, Arnaldi G, Osella G, Masini AM \& Ali A. A survey on adrenal incidentaloma in Italy. Journal of Clinical Endocrinology and Metabolism 200085 637-644.

11 Herrera MF, Grant CS, van Heerden JA, Sheedy PF \& Istrup DM. Incidentally discovered adrenal tumors: an institutional perspective. Surgery $19911101014-1021$.

12 Gláz E, Rácz K, Varga I, Kiss R, Tóth M \& Fütö L. Mineralocorticoid production of adrenal cortical adenomas. Journal of Steroid Biochemistry $1993 \mathbf{4 5} 57-84$.

13 Reincke M, Nieke J, Krestin GP, Saeger W, Allolio B \& Winkelman W. Preclinical Cushing's syndrome in adrenal incidentalomas. Comparison with adrenal Cushing's syndrome. Journal of Clinical Endocrinology and Metabolism 199275 826-832.

14 Hensen J, Buhl M, Bahr V \& Oelker W. Endocrine activity of the silent adrenocortical adenoma is uncovered by response to corticotropin-releasing hormone. Klinische Wochenschrift 1990 68 608-614.

15 Osella G, Terzolo M, Borretta G, Magra G \& Piovesan AA. Endocrine evaluation of incidentally discovered adrenal masses (incidentalomas). Journal of Clinical Endocrinology and Metabolism $1994791532-1539$.

16 Tóth M, Rácz K, Adleff V, Varga I, Fütö L, Jakab C et al. Comparative analysis of plasma 17-hydroxyprogesterone and cortisol responses to ACTH in patients with various adrenal tumors before and after adrenalectomy. Journal of Endocrinological Investigation $200023287-294$.

17 Bernini GP, Brogi G, Vivaldi MS, Argenio GF, Sgro M, Moretti A et al. 17-Hydroxyprogesterone response to ACTH in bilateral and monolateral adrenal incidentalomas. Journal of Endocrinological Investigation $1996 \mathbf{1 9} 745-752$.

18 Del Monte P, Bernasconi D, Bertolazzi L, Meozzi M, Badaracco B \& Torne R. Increased $17 \alpha$-hydroxyprogesterone response to ACTH in silent adrenal adenoma: cause or effect? Clinical Endocrinology $199542273-277$.

19 Reincke M, Peter M, Sippel WG \& Allolio B. Impairment of $11 \alpha-$ hydroxylase but not 21-hydroxylase in adrenal incidentalomas. European Journal of Endocrinology 1997136 196-200.

20 Seppel T \& Schlghecke R. Augmented 17-alpha-hydroxyprogesterone response to ACTH stimulation as evidence of decreased 21-hydroxylase activity in patients with incidentally discovered adrenal tumours (incidentalomas). Clinical Endocrinology 1994 $41445-451$.

21 Terzolo M, Osella G, Ali A, Borretta G, Magro G-P, Termine A et al. Different patterns of steroid secretion in patients with adrenal incidentalomas. Journal of Clinical Endocrinology and Metabolism $199681740-744$.

22 Turton DB, O’Brian JT \& Shakin KMM. Incidental adrenal nodules: association with exaggerated 17-hydroxyprogesterone response to adrenocorticotropic hormone. Journal of Endocrinological Investigation $199215789-796$.

23 Jaresch S, Kornely E, Kley H-K \& Schlaghecke R. Adrenal incidentalomas and patients with homozygous or heterozygous congenital adrenal hyperplasia. Journal of Clinical Endocrinology and Metabolism 1992 74 685-689.

24 Beuschlein F, Schulze E, Mora P, Gensheimer H-P, Maser-Gluth C, Allolio B et al. Steroid 21-hydroxylase mutations and 21hydroxylase messenger ribonucleic acid expression in human adrenocortical tumors. Journal of Clinical Endocrinology and Metabolism $1998 \mathbf{8 3}$ 2585-2588.

25 Kjellman M, Holst M, Backdahl M, Larsson C, Farnebo L-O \& Wedell A. No overrepresentation of congenital adrenal hyperplasia in patients with adrenocortical tumours. Clinical Endocrinology $199950343-346$. 
26 Vecsei P. Glucocorticoids: cortisol, cortisone, corticosterone, compound S and their metabolites. In Methods of Hormone Radioimmunoassay, pp 767-796. Eds BM Jaffe \& HR Behrman. New York: Academic Press, 1979.

27 Vecsei P, Onyechi J, Hornung J, Dietz R, Mast G \& Hobler H. Use of corticosteroid antibodies for the study of corticosteroid biosynthesis in vitro. Journal of Steroid Biochemistry 19756 383-387.

28 Wedell A, Thilén A, Stengler B, Ritzén E \& Luthman H. Mutational spectrum of the steroid 21-hydroxylase gene in Sweden: implication for genetic diagnosis and association with disease manifestation. Journal of Clinical Endocrinology and Metabolism 199478 1145-1152.

29 Wedell A \& Luthman H. Steroid 21-hydroxylase deficiency: two additional mutations in salt-wasting disease and rapid screening of disease-causing mutations. Human Molecular Genetics 19932 499-504.

30 White PC \& New MI. Genetic basis of endocrine disease 2: congenital adrenal hyperplasia due to 21-hydroxylase deficiency. Journal of Clinical Endocrinology and Metabolism 1992 74 6-11.

31 Abo K, Sumino K, Nishio H, Hozumi T, Ishida Y, Fujieda T et al. 21-Hydroxylase deficiency presenting as massive bilateral adrenal masses in the seventh decade. Endocrine Journal $1999 \mathbf{4 6}$ 817-823.

32 Mokshagundam S \& Surks MI. Congenital adrenal hyperplasia diagnosed in a man during workup for bilateral adrenal masses. Archives of Internal Medicine 1993153 1389-1391.

33 Ravichandran R, Lafferty F, McGinnis MJ \& Taylor HC. Congenital adrenal hyperplasia presenting as massive adrenal incidentalomas in the sixth decade of life: report of two patients with 21-hydroxylase deficiency. Journal of Clinical Endocrinology and Metabolism $1996 \mathbf{8 1} 1776-1779$.

34 Miller WL. Genetics, diagnosis, and management of 21-hydroxylase deficiency. Journal of Clinical Endocrinology and Metabolism $199478241-246$.

35 Rumsby G, Avey CJ, Conway GS \& Honour JW. Genotype-phenotype analysis in late onset 21-hydroxylase deficiency in comparison to the classical forms. Clinical Endocrinology $1998 \mathbf{4 8} 707-711$.

36 Witchel SF \& Lee PA. Identification of heterozygotic carriers of 21 hydroxylase deficiency - sensitivity of ACTH stimulation test. American Journal of Medical Genetics 199876 337-342.
37 New MI \& Speiser PW. Genetics of adrenal steroid 21-hydroxylase deficiency. Endocrine Reviews $19867331-349$.

38 Witchel SF, Lee PA, Suda-Hartman M \& Hoffmann EP. Hyperandrogenism and manifesting heterozygotes for 21-hydroxylase deficiency. Biochemical and Molecular Medicine 199762 151-158.

39 Dumic M, Brkljacic L \& Speiser PW. An update on the frequency of nonclassic deficiency of adrenal 21-hydroxylase in the Yugoslav population. Acta Endocrinologica 1990122 703-710.

40 Sherman SL, Aston CE, Morton NE, Speiser PW \& New MI. A segregation and linkage study of classical and nonclassical 21hydroxylase deficiency. American Journal of Human Genetics 1988 42 830-838.

41 Speiser PW, New MI, Tannin GM, Pickering D, Yang SY \& White PC. Genotype of Yupik Eskimos with congenital adrenal hyperplasia due to 21-hydroxylase deficiency. Human Genetics 1992 88 647-648.

42 Speiser PW, Dupont B, Rubinstein P, Piazza A, Kastelan A \& New MI. High frequency of nonclassical steroid 21-hydroxylase deficiency. American Journal of Human Genetics 198537 $650-667$.

43 Fitness J, Dixit N, Webster D, Torresani T, Pergolizzi R, Speiser PW et al. Genotyping of CYP21, linked chromosome $6 \mathrm{p}$ markers, and a sex-specific gene in neonatal screening for congenital adrenal hyperplasia. Journal of Clinical Endocrinology and Metabolism 199984 960-966.

44 Ferenczi A, Garami M, Kiss E, Pék M, Sasvári-Székely M, Barta C et al. Screening for mutations of 21-hydroxylase gene in Hungarian patients with congenital adrenal hyperplasia. Journal of Clinical Endocrinology and Metabolism 199984 2369-2372.

45 Rácz K, Pinet F, Marton T, Szende B, Gláz E \& Corvol P. Expression of steroidogenic enzyme messenger ribonucleic acids and corticosteroid production in aldosterone-producing and nonfunctioning adrenal adenomas. Journal of Clinical Endocrinology and Metabolism 199377 677-682.

Received 31 January 2002

Accepted 16 May 2002 